\title{
SEASONAL VARIATIONS IN THE PHYSICO-CHEMICAL PARAMETERS OF \\ GROUNDWATER AT UJJAIN INDIASEASONAL VARIATIONS IN THE \\ PHYSICO-CHEMICAL PARAMETERS OF GROUNDWATER AT UJJAIN INDIA \\ Madhubala Purohit and Neelam Sharma \\ Govt. Madhav Science College, Ujjain, MP, India. \\ Corresponding author Email : tanirakesh@ymail.com
}

\begin{abstract}
:
Large number of urban and rural population of India extensively uses groundwater, many of the times untreated, for drinking and other domestic purposes. Ground water contamination is mainly due to the result of human activities. Most of the consumers are unaware of the quality. Long term availability of the groundwater is also uncertain. In many countries groundwater awareness, exploitation and pollution is being assessed by conducting public opinion surveys and water quality analysis. In the present work, an attempt was made to assess the groundwater quality issue of Ujjain city in pre- and post-monsoon seasons of 2010. Physico-chemical characteristics of groundwater samples in the study area were analyzed as per standard methods of APHA and results were compared with WHO and BIS standards. TDS in most of the samples was higher than the desirable limit (500mg/1) in both the seasons. In general, values for pH, TA, TH, Cl--, SO4--, PO4, NO2--, were found to be higher in post monsoon season as compared to pre -monsoon season.
\end{abstract}

\section{Keywords:}

APHA, BIS, desirable limit, groundwater contamination, physico-chemical parameters, pre- and post-monsoon seasons, WHO.

\section{Introduction:}

Increase in human population and their desire for a better standard of living resulted into the expansion of economic activities both in scale and diversity. 
Therefore, the demands for freshwater resources continue to grow. Among various sources of water, groundwater is said to be the safest water for drinking and domestic purposes. Nevertheless, several factors like discharge of agricultural, domestic and industrial wastes, land use practices, geological formation, rainfall patterns and infiltration rate are reported to affect the quality of groundwater in an area. (Bhateja et.al 2008, Jothi Venketachlam and Suresh 2008) The quality of drinking water plays an important role in maintaining sound health. Safe water is one which should be free from faecal contamination and conform to the limits of contamination (Murgeson et al., 2004). The water quality is deteriorating due to improper water management, unscientific water disposal and lack of environment awareness. This has lad to scarcity of potable water affecting human health (Agarkar \& Thombre 2005). Nearly $70 \%$ of infectious diseases in rural India are water borne and major problem is due to the excess of fluoride, arsenic, nitrate (Bhateja et al., 2008) and fecal contamination (Suresh et al., 2009) in groundwater. The present study was aimed to assess the groundwater quality of rural areas of Ujjain in pre- and post-monsoon seasons so as to evaluate the effect of climatic conditions on the groundwater quality.

\section{Material and Method:}

STUDY AREA - Geography- Ujjain is located at $23011^{\prime \prime}$ north longitude and 75050" latitude. [3] It has an average elevation of 491 meters (1610") from mean

sea level. The Tropic of cancer passes through Ujjain. Ujjain is situated on the Malwa Plateau in Central India. The soil is black and stony. The vegetation is typical of arid regions with thorny trees like Acacia dominating the landscape. Soybean, wheat, jowar and bajra are the main crops grown. 2.2 Climate- Ujjain experiences a warm sub-tropical climate, typical of the interior Indian subcontinent. Summer starts in late March with temperature rising to $45^{\circ} \mathrm{C}$ at its peak in May. The monsoon arrives in the middle of June and continues till early October. About $870 \mathrm{~mm}$ (35 inches) of precipitation is received during 
those months. 3. MATERIAL AND METHODS 3.1 Collection of samples: - The water samples were collected from Gonsa, Azampura and Sadawal (Figure: 1) in pre-monsoon (may 2010) and post-monsoon seasons (November 2010). The sampling was done in the morning hours and the samples were collected in plastic container and brought to the laboratory for further analysis. 3.2 Physico- chemical analysis - analysis of water samples was carried out according to standard methods of APHA (1998) and results were compared with the standards of BIS (1982) and WHO (2006) Table -1).

\section{Result and Discussion:}

The $\mathrm{pH}$ values varied from 6.84 to 8.19 in pre- monsoon and 7.10 to 8.82 in post-monsoon. The $\mathrm{pH}$ was found to be maximum for G1 sample in both pre and post- monsoon seasons (figure: 3). The observed $\mathrm{pH}$ values of all samples were within the prescribed limit of WHO and BIS. Total dissolved solids in water samples were in the range of 256 to $1717 \mathrm{mg} / \mathrm{L}$ in pre -monsoon and 297 to $1945 \mathrm{mg} / \mathrm{L}$ in post monsoon season. TDS values of all samples were higher than the permissible level in both the seasons except (A3, in pre- monsoon and A2, A3 in post monsoon season Table-2). Higher TDS may affect persons who are suffering from kindly and heart diseases (Gupta et al 2004). Water containing high solids may cause laxative or constipation effects. (Kumarasamy, 1989). Alkalinity values were recorded in the range of 150 to $456 \mathrm{mg} / 1$ in pre-monsoon and 210 to $494 \mathrm{mg} / 1$ in post-monsoon seasons. The higher values of alkalinity may be due to the presence of bicarbonate, carbonate and hydroxide in the water bodies (Jain et al., 2000). The total hardness of water samples was in the range of 152 to $1280 \mathrm{mg} / 1$ in premonsoon and 210 to $1350 \mathrm{mg} / 1$ in post-monsoon seasons. The adverse effects of hardness are formation of kidney stone and heart diseases (freeda Gnona Rani et al., 2003, Sastry and Rathee 1998). The higher hardness value in summer season might be due to rising temperature thereby increasing the solubility of calcium and magnesium salts (Garg, 2003). Higher value of 
calcium hardness was found in post-monsoon season and magnesium hardness was found higher in pre-monsoon season (except A3, S1 and S2, Figure: 4). Nitrite -nitrogen varied from 3.6 to $36 \mathrm{ug} / 1$ in pre- monsoon seasons and 1.5 to $100 \mathrm{ug} / 1$ in post- monsoon seasons.S3 and S1 sample showed drastic increase in postmonsoon season. Ammonical-nitrogen was found in pre-monsoon samples only (except G3 sample of post-monsoon season). Chloride values were found to be higher in post-monsoon season (except G1 and G3, Figure-3). Maximum chloride value was found in G2 sample $(1827 \mathrm{mg} / 1)$ in post-monsoon season. High chloride gives salty taste to water and may result in hypertension, osteoporosis, renal stones and asthma (McCarthy 2004) Sulphate values were found to be higher in post-monsoon season (except S1 sample). In Sadawal sample we found higher values because it is very close to municipal sewage treatment plant. Similar results were found for phosphate in Sadawal sample (Figure 4). Phosphate was found in postmonsoon season only (except Sadawal samples Table-3). CORRELATIONS:

Correlation Matrix among nine water quality parameters of groundwater samples clearly indicated that Phosphate showed positive correlation with Total hardness $(r=0.9784)$ and Chloride $(r=0.9872)$ and negative correlation with Total alkalinity $(r=-0.9477)$ in pre-monsoon season. Ammonical-nitrogen was positively correlated with Total hardness $(r=0.9796)$. Magnesium hardness was positively correlated with Phosphate $(r=0.9958)$, Total hardness $(r=0.9896)$ and Ammonical nitrogen $(\mathrm{r}=0.9712)$ in pre-monsoon season. In post monsoon season we found only one positive correlation between Magnesium hardness and Total hardness ( $\mathrm{r}=0.9539)$.

\section{Conclusion:}

Conclusions and Recommendations:

Regular monitoring of groundwater is necessary.

- Proper treatment of domestic and municipal sewage is necessary.

- Develop awareness in rural people about groundwater quality. 
- Groundwater sources of Sadawal should be avoided for drinking purpose because of probable contamination from sewage treatment plant which is situated in sadawal village itself.

\section{References:}

American Public Health Association (APHA), 30 March (1985).Water pollution control federation,

Agarkar, V.S. and Thombre, B.S. (2005): Status of drinking water quality in schools in Buldhan District of Maharashtra. Nature Environment and pollution Technology, 4(1):495-499.

Batheja, Kavita, Dr. A. K. Sinha and Dr. Gita Seth (2008): Nitrate and fluoride contamination in groundwater of Churu Block, Rajasthan. Journal of Indian Water works Association Jan. March

BIS, specification for drinking water, 1991.ISI: 10500.

Freeda Gnona Rani, D., Thamariselvi, C. and Ebanasar, J. (2003): Cited in study of probability of water source in cement industrial area, Ariyalur. Jr. Indus. Poll. Contrl. 17(2): 257.

Garg, S. S. (2003): Water quality of wells and borewells of 10 selected locations of Chitrakoot region. Indian Jr. Env. Protec. 23(9): 966-974.

Gupta, S., Kumar, A Ojha, C K and Singh, G. J. (2004): Environmental Science and Engineering. 46(1), 74-78 (4 pages)

Jain, C.K. (2000): Groundwater quality in Sagar districts, Madhya Pradesh, India. Journal Env. Health, 42(4): 151-158.

Jothivenkatachalam K. and K. Suresh (2008): Status of the groundwater quality in Kuniomuthur and Madakkari areas of Coimbatore, Tamilnadu. Nature, Environment and pollution technology. Vol. 7, No. 2, pp. 283286. 
Kumaraswamy, N. (1989): Ascending pollution potential from basic panactic ratio- A case study. Indian Jr. Env. Protec. 9: 178-181.

Mc Carthy, M.F. (2004): Should we restrict chloride rather than sodium and medical Hypothesis, 63: 138-148.

Murgesan, S.D., Kumar, D.S., Rajan, S. and Chandrica, D. (2004): Comparitive study of the groundwater resources of east and west region of Chennai, Tamilnadu, Nature, Environment and pollution technology, 3(4): 495-499.

Sastry, K.V. and Rathee, P. (1998): Physico-chemical and microbiological characteristics of water of village Kenneli (District Rohtak) Haryana. Proc. Academy of environment Biology, 7(1): 103-108.

Suresh T. N.M. Kottureshwara, M. Revanasiddappa and Suresh (2009): Physico-chemical characteristics of bore well waters of Bellary Taluk, Karnataka, India. Nature, Environment and pollution technology. Vol.8, No.3, pp. 417-428.

WHO (1996): Guidelines for drinking water Quality. 2nd edn. World Health Organization, Geneva.

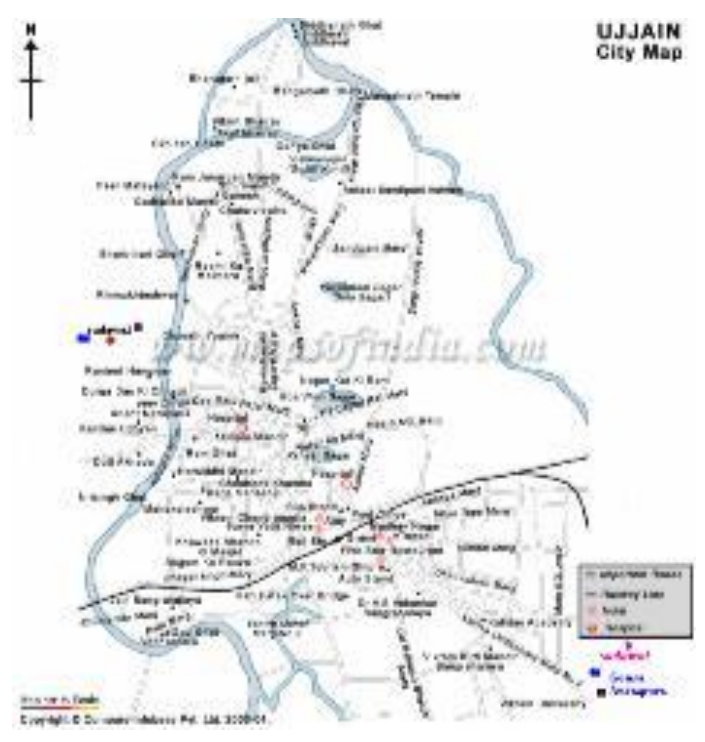

Figure 1: Location Map of Ujjain 


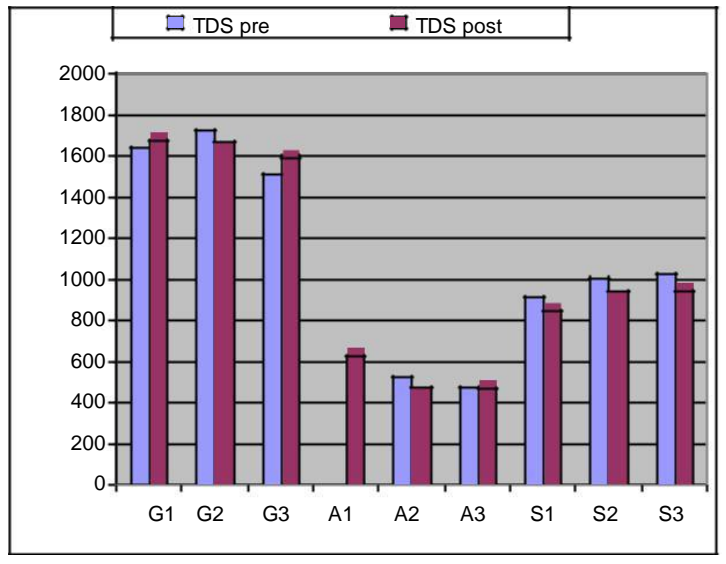

A

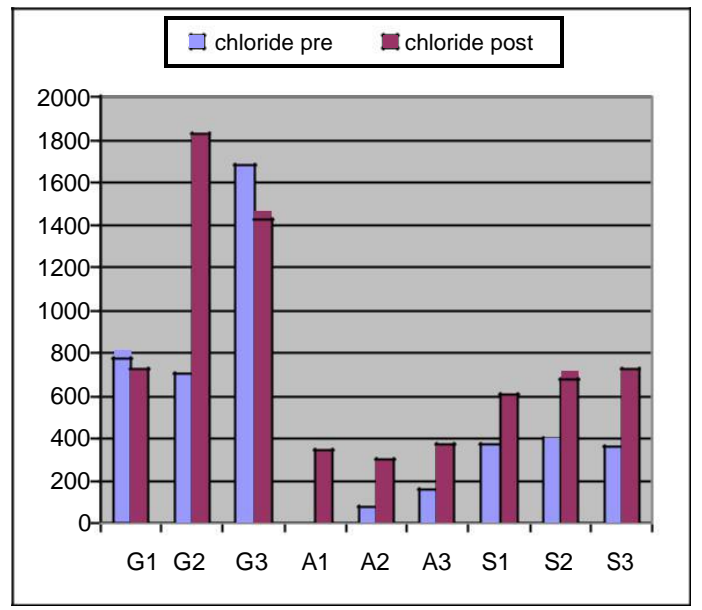

$\mathrm{C}$

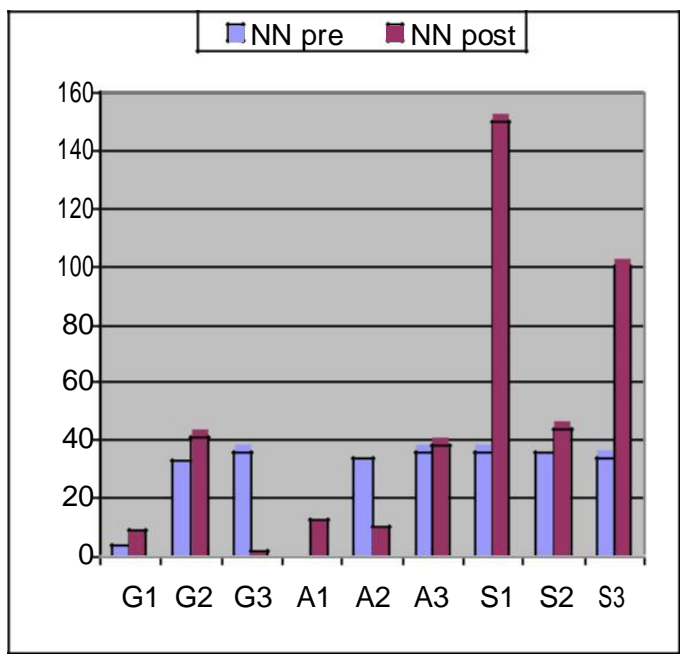

$\mathrm{E}$

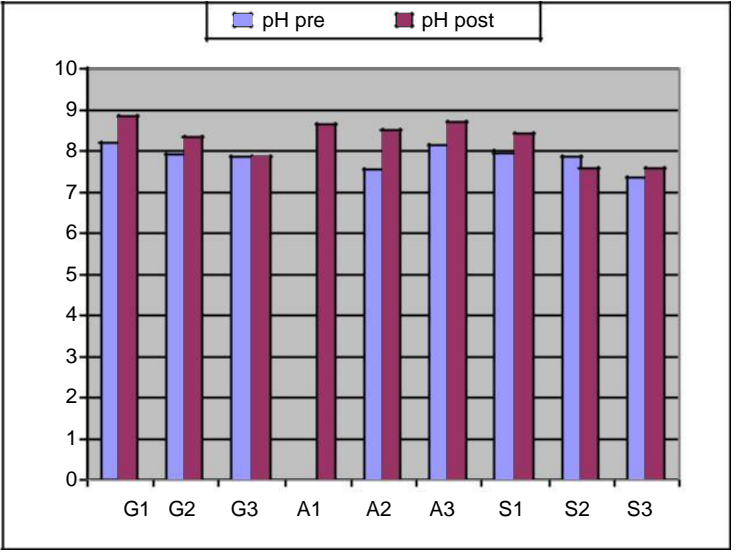

$\mathrm{B}$

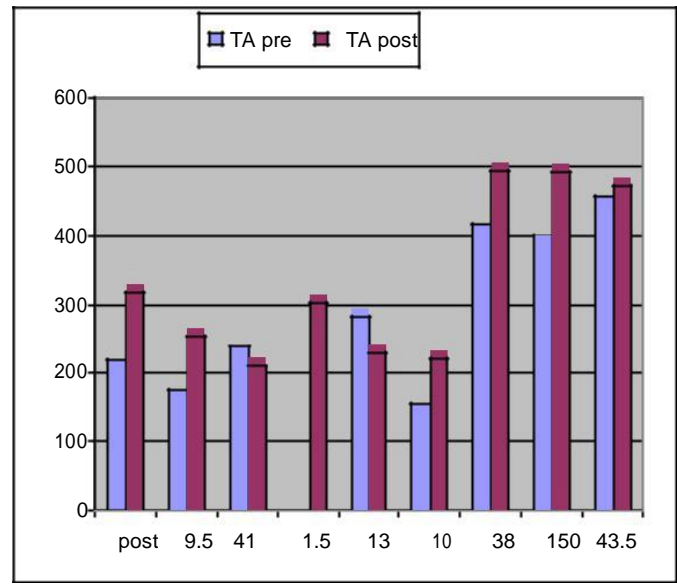

$\mathrm{D}$

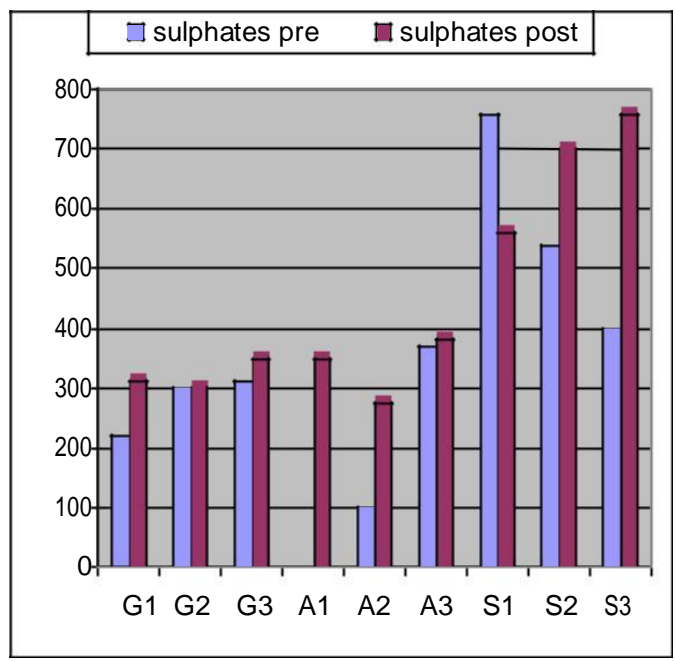

$\mathrm{F}$

Figure: 3 Seasonal variations in TDS (A), pH (B), Chloride (C), Total Alkalinity (D), Nitrite-nitrogen (E) and Sulfate (F) of groundwater samples of Ujjain 

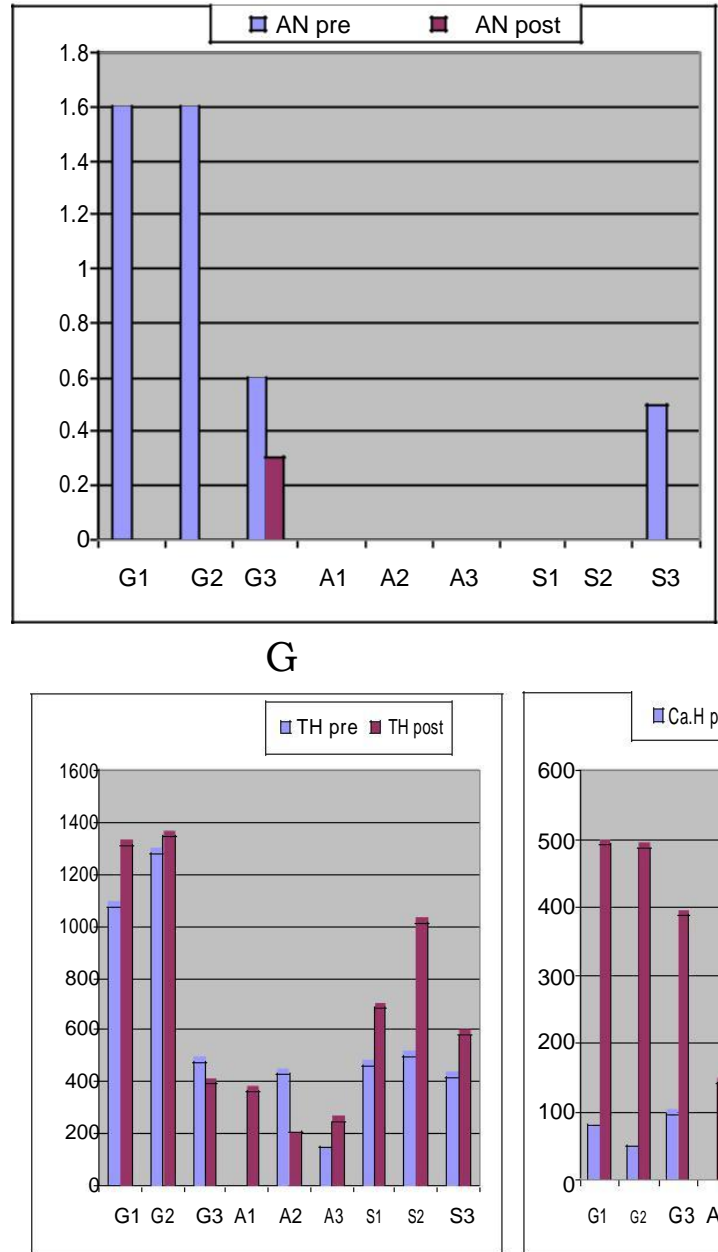

I

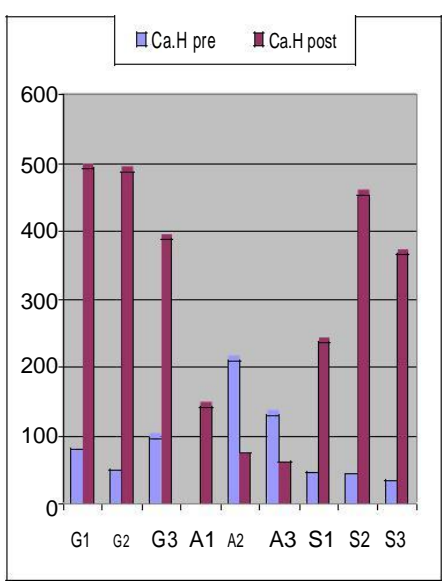

$\mathrm{J}$

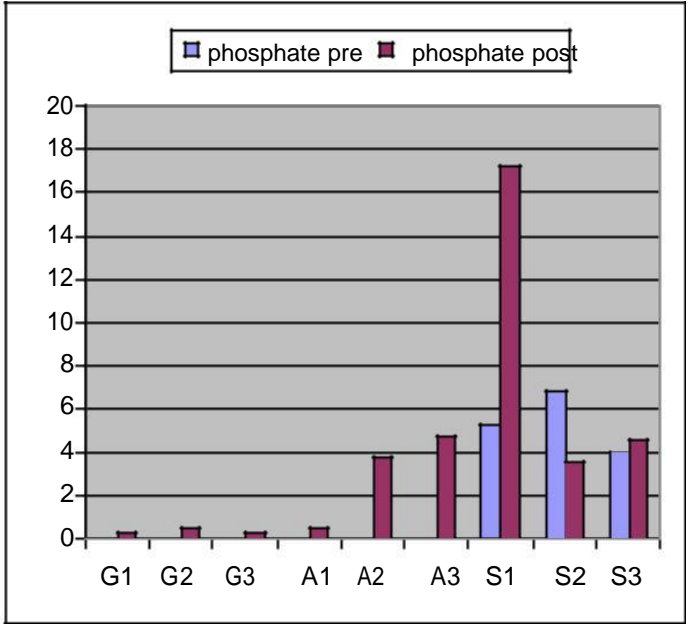

$\mathrm{H}$

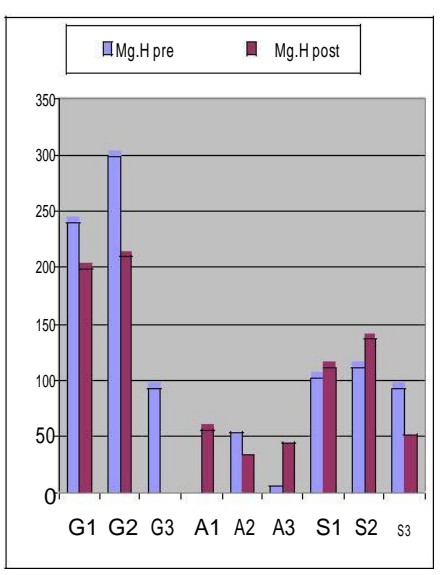

$\mathrm{K}$

Figure: 4 Seasonal variations in Ammonical nitrogen (G), Phosphate (H), Total hardness (I), Ca- hardness and (J), Mg -hardness (K) of groundwater samples of Ujjain 